\title{
Long-term effects on nursing alumni: Assessing a course in public and global health
}

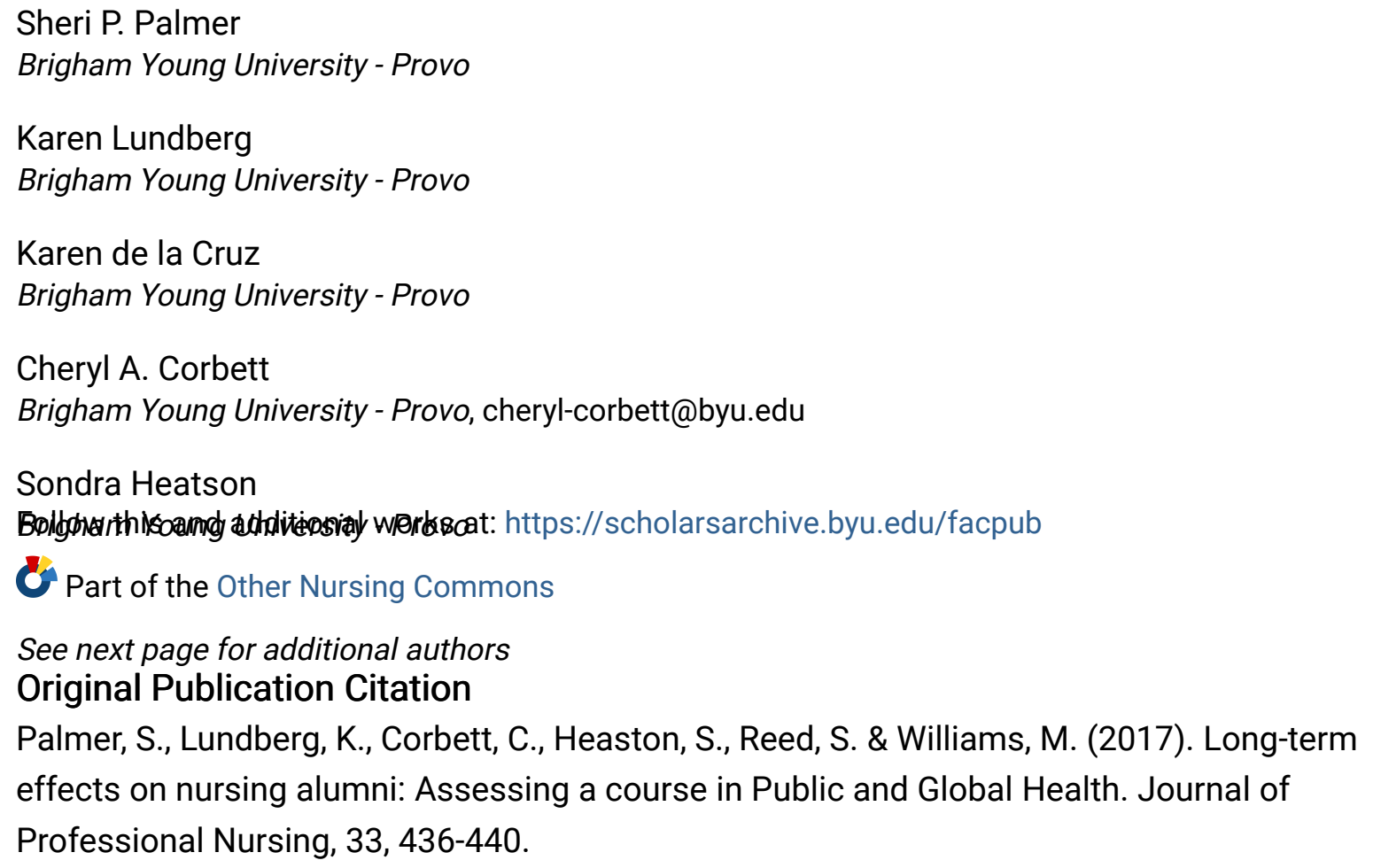

\section{BYU ScholarsArchive Citation}

Palmer, Sheri P.; Lundberg, Karen; de la Cruz, Karen; Corbett, Cheryl A.; Heatson, Sondra; Reed, Shelly; and Williams, Mary, "Long-term effects on nursing alumni: Assessing a course in public and global health" (2017). Faculty Publications. 5077. https://scholarsarchive.byu.edu/facpub/5077

This Peer-Reviewed Article is brought to you for free and open access by BYU ScholarsArchive. It has been accepted for inclusion in Faculty Publications by an authorized administrator of BYU ScholarsArchive. For more information, please contact ellen_amatangelo@byu.edu. 


\section{Authors}

Sheri P. Palmer, Karen Lundberg, Karen de la Cruz, Cheryl A. Corbett, Sondra Heatson, Shelly Reed, and Mary Williams 


\title{
Long-term effects on nursing alumni: Assessing a course in public and global health is
}

\author{
Sheri P. Palmer *, Karen Lundberg, Karen de la Cruz, Cheryl Corbett, Sondra Heaston, Shelly Reed, Mary Williams \\ College of Nursing, Brigham Young University, Box 500, SWKT, Provo, UT 84602, USA
}

\section{A R T I C L E I N F O}

\section{Article history:}

Received 7 December 2016

Accepted 28 March 2017

\section{Keywords:}

Study abroad

Long-term effects

Professionalism

\begin{abstract}
A B S T R A C T
The impact of a cultural awareness course among nursing students may affect the particular person for years to come. Cultural awareness can be taught via many methods, often requiring study abroad and/or extreme investment of time, money and effort. There is little research on sustained effects on nursing alumni from such a course. The purpose of this descriptive survey study was to determine the long term outcomes of a cultural awareness course and 2) compare the long term effects between alumni who went abroad and those who chose to complete the course locally. One hundred and twenty-one nursing alumni completed the International Education Survey (IES) (Zorn, 1996) with additional open-ended questions. Quantitative and qualitative results concluded: 1 ) nursing alumni were influenced long term by a course dedicated to public and global health and 2) all alumni had statistically significant IES scores but alumni who studied abroad had the greatest increase.
\end{abstract}

(c) 2017 Elsevier Inc. All rights reserved.
The impact of a cultural awareness course among nursing students may affect the particular person for years to come. We found it is important to measure the sustained effects of aspects of a public and global health course. There are many intensive efforts of faculty, administration and students that combine to create a successful course with a large contingent of study abroad participants. This study has assessed differences and similarities of long term affects between students who have studied abroad and those that studied locally.

According to the last census the population of the United States increased by 27.3 million between 2000 and 2010 . While there has been an increase in the Caucasian population, those considered racially diverse have increased in a more dramatic way (Humes, Jones, \& Ramirez, 2011). With increased diverse populations, culturally appropriate healthcare and educational preparation that ensures cultural competence is essential. In fact, many professional accreditation standards now require that cultural competency skills be an integral part of the undergraduate nursing curriculum (American Association of Colleges of Nursing, 2010; Betancourt, Green, Carillo \& Park, 2005; National League for Nursing, 2009; U.S Department of Health and Human Services, Agency for Healthcare Research and Quality, 2011). A variety of teaching strategies and experiences are currently being used to assure cultural proficiency, with one option being a dedicated course providing a cultural immersion experience for students.

\footnotetext{
th This research did not receive any specific grant from funding agencies in the public commercial, or not-for-profit sectors.

* Corresponding author.

E-mail address: sheri-palmer@byu.edu (S.P. Palmer).
}

\section{Literature review}

Research within the past ten years indicate rising numbers of studies on immediate effects of study abroad upon nursing students (Kohlbry, 2016; Kulbok, Mitchell, Glick, \& Greiner, 2012; Peek \& Park, 2013; Riner, 2011). However, there is a paucity of research on long term impacts of study abroad among nurses. One of the first studies on sustained effects was published in 1996. Zorn (1996) studied the long term impact of an international immersion experience on 27 alumni using the International Education Survey tool (IES). The IES measured the influence of an international experience on four domains: professional role, international perspective, and personal and intellectual development. Although all four domains were found to be influenced by the experience, the highest impact was on enhanced international perspective and increased personal development with a lower impact found in the professional nurse role and intellectual development dimensions.

Zorn's original study tool (1996) was modified and replicated by DeDee and Stewart (2003) utilizing the IES in a study sample of 38 nursing alumni. They found a similar international study impact in all four IES domains. Smith and Curry (2011) used the original IES and collected data from 36 alumni who participated in an international two week clinical experience. Results indicated the dimension of professional role was most significantly impacted by study abroad experiences and concluded nurses' future professional and personal development were positively influenced.

Other studies not using the IES also show long term learning with themes of: embracing others, gaining cultural competencies, experiencing an ethnocentric shift and negotiating ethical dilemmas (Caldwell \& 
Purtzer, 2014) and coming to understand unsettled feelings and advocating for change (Evanson \& Zust, 2006).

\section{Our course}

In 2005 our college of nursing integrated a required public and global health course into the baccalaureate nursing curriculum. Previously, the course was elective, however because of positive faculty and student outcomes, as well as the need for cultural competence among today's nursing workforce, the course was changed from elective to a required course for all nursing students. The course has four purposes: first, exposing students to global health and health disparity issues; second, assisting students in understanding how culture impacts the health of a person, family and community; third, providing an opportunity for service learning that promotes self-empowerment of individuals; and fourth, providing students the opportunity to become more culturally competent. Students have opportunities to study global health internationally as well as locally with at least ten choices to rank in order of interest. Some of the international sites we have used over the past ten years have included Ecuador, Ghana, Taiwan, Tonga, Finland, Russia, Czech Republic, Samoa, England, Australia, India, and Vietnam. Our local sites have included working with the veteran, at-risk (prison, homeless, etc.), and refugee/immigrant populations. This course is taught once a year in spring term after the sixth or seventh semester in the curriculum.

In the semester prior to the public and global health clinical course, a site/country-specific cultural class is required for all students. This course includes topics such as: general concepts of the culture of interest, specific healthcare needs, psychosocial issues, resources, alternative healthcare practices, music, food, and art specific to the location. Learning activities include computer-based modules, discussion of articles, and student presentations on different culture topics such as geography, political issues, healthcare, and customs.

The public and global health study abroad groups typically stay in their particular country three to four weeks, while local groups participating with at-risk populations or refugee/immigrant populations participate in their clinical experience for the full seven week term. Students are required to spend approximately $80-100 \mathrm{~h}$ in clinical time either abroad or locally. The clinical experiences may include working alongside nurses and/or nursing students in the hospitals, serving in the community, health fairs, and various other health related teaching and screenings for individuals, families, and healthcare professionals. This course encourages and integrates cultural competency as a life-long learning process and encourages professionalism. Students in all areas have the opportunity to interact with communities, healthcare professionals, and various nonprofit organizations.

The purpose of this descriptive survey study was to evaluate and compare the long-term outcomes of a required public and global health course in the areas of professional role development, personal and intellectual development, and international perspectives. Also the differences between local and international experiences were assessed in relation to long term outcomes. Specific research questions asked were: What long-term affects does study abroad have on alumni who have graduated from our nursing program? And, what long-term differences exist between students who have studied abroad and those who have not?

\section{Methods}

Design

A descriptive survey design was used to determine the long term outcomes (one to seven years post-graduation) of a public and global health course on baccalaureate nursing alumni. After obtaining internal review board approval from Brigham Young University, and individual informed consent, data were collected using a demographic survey, a slightly modified version (permission granted) of the International Education Survey (IES) (Zorn, 1996), and open-end questions which allowed for alumni to provide additional perspectives and insights about the experience. Some of the questions included: What else is important for us to know about your international education experience? What are the most important things you have learned from your experience? and, How has this experience helped you develop new problemsolving skills?

\section{Participants}

Participants were all baccalaureate nursing alumni who graduated within the past seven years (2007-2014) who had participated in an international or local experience years. Surveys were distributed to 971 graduates with those not completing the survey receiving a six week follow up reminder. One hundred thirty-seven alumni started the survey with 121 completing the survey for a $12.9 \%$ response rate. Anonymity of respondents was maintained by assigning coded numbers to each survey.

Respondents ranged in age from 22 to 66 years with $88 \%$ females and $12 \%$ males. Ninety-five percent described themselves as Caucasian with $5 \%$ coming from other ethnic backgrounds. All participants identified their religious preference as the predominant local religion. Also assessed was current employment, speaking other languages, and cultural diversity of friends and neighborhoods where the alumni grew up.

\section{Instruments}

The International Education Survey (IES) (Zorn, 1996) was used to assess the outcomes of the both local and international global experiences. The survey contains 29 items with four dimensions including professional nurse role ( 5 items), international perspective ( 7 items), personal development (13 items), and intellectual development (4 items) and used a 1 to 7 Likert scale. Open-ended questions allowed respondents to describe additional perspectives.

Previous reliability estimates for the IES have been established with the total alpha coefficient being 0.97 . Coefficients for the four dimensions include: professional nurse role $(0.88)$; international perspective (0.89); personal development (0.94); and intellectual development (0.85) (Zorn, 1996). The reliability coefficients among this sample were: IES overall, 0.98; professional nurse role, 0.96; international perspective, 0.93; personal development, 0.95; and intellectual development, 0.84 . Definitions of the four constructs measured are: 1 -nursing role means nurses who are educated at the baccalaureate level are prepared to provide professional nursing in a variety of health care settings; 2 - international perspective is a global understanding or changed perceptions about one's own or the host culture; 3 - personal development means personal decisions, philosophy, values, and beliefs are influenced; and 4 - intellectual development is demonstrated through critical or systematic thinking, language study, or a change in reading habits (Zorn, 1996).

\section{Data analysis}

Descriptive statistical analysis of data was conducted using Statistical Package for the Social Sciences (SPSS, 2007) (see Table 1). Independent $t$-tests compared overall scores and IES subscales from those who participated in study abroad versus local venues. The open ended questions were submitted to content analysis using methods developed by Huberman and Miles (1994). Responses to the open-ended questions were read line by line to identify categories, themes and patterns. Separate analyses were done by two researchers which were then compared and discussed to achieve consensus. Trustworthiness of the data was established by investigator triangulation. 
Table 1

Comparison of international education survey scores using independent t-tests.

\begin{tabular}{|c|c|c|c|c|c|}
\hline \multirow[t]{2}{*}{ Subscale } & \multicolumn{2}{|c|}{ Study abroad $(n=75)$} & \multicolumn{2}{|c|}{ Non-study abroad $(n=46)$} & \multirow[t]{2}{*}{$\mathrm{p}^{\mathrm{a}}$} \\
\hline & Mean & SD & Mean & SD & \\
\hline Nursing role & 5.29 & 1.41 & 4.53 & 1.77 & 0.010 \\
\hline International perspective & 5.07 & 1.03 & 4.04 & 1.58 & 0.000 \\
\hline Personal development & 4.76 & 1.36 & 3.74 & 1.67 & 0.000 \\
\hline Intellectual development & 4.29 & 1.39 & 3.14 & 1.57 & 0.000 \\
\hline Overall & 4.91 & 1.12 & 3.91 & 1.54 & 0.000 \\
\hline
\end{tabular}

${ }^{a}$ Comparisons made using independent $t$-tests.

\section{Results}

\section{Demographic results}

There was a wide range in age of respondents which was sought for. We wanted to show a range of life and career experience which would portray a more diverse alumni mix. In addition, the diverse age and backgrounds of the alumni helped to eliminate homogeneity of the respondents.

\section{Quantitative results}

The question of "what long-term differences exist between students who have studied abroad and those who have not" is answered by the difference in the IES scores between the two groups. Study abroad alumni scored higher on the overall score for the IES and on all subscales compared to domestic alumni (see Table 1).

The IES score is further broken down into four dimensions: nursing role, international perspective, personal development, and intellectual development. Comparisons were statistically significant between domestic and international alumni. Alumni that had studied internationally scored significantly higher on all four of these dimensions (see Table 1). Among alumni who studied abroad, the professional nurse role dimension of the IES found that the highest impact (mean) (on a 1-7 scale with 7 representing the highest attribute) was that of the nursing role (5.29), followed by international perspective (5.07), personal development (4.76), and intellectual development (4.29). The overall score was 4.91. Likewise alumni who remained domestic had the same impact order as those going internationally but scored statistically lower on all dimensions including: nursing role (4.53), international perspective (4.04), personal development (3.74), and intellectual development (3.14). The overall score of those alumni who studied locally was 3.91 .

\section{Qualitative results}

Content analysis of qualitative comments, whether the alumni studied abroad or locally, answers the question of "What long-term affects does study abroad have on alumni who have graduated from our nursing program?" A rich variety of themes were unveiled. An explanation of themes and supporting comments are discussed below. Theme discussions are arranged from most frequently reported to least reported (see Table 2).

Written comments from open-ended questions on the surveys revealed several themes. The themes showed the positive impact the global health course had made in the personal and professional lives of the alumni.

\section{Understanding and valuing differences and similarities}

Alumni comments revealed "understanding and valuing differences and similarities" as the primary theme. Many comments revealed new insights and understandings regarding the impact of culture and health care systems on society. One alumni commented, "Living among another culture helped me understand the reasoning and underlying values for actions and practices. It has given me a more compassionate, accepting, understanding, and appreciative view of different cultures and beliefs." Another alumnus expressed, "I learned to love people from all backgrounds and cultures, to embrace differences, and to be respectful of other people's opinions and beliefs."

\section{Becoming aware}

Increased awareness was the second most common theme identified, as alumni experienced the concept of changed perceptions and transformation through awareness. Exposure to different cultures, socio-economic conditions and health care systems were experiences that facilitated a change in their perspective. One alumni said, "I worked with the refugees...which opened my eyes to the cultural diversity all around us in the USA." Another alumnus commented, "It opened my eyes to a world that I had never experienced. I still talk about my experiences often, which tells what an impact it had on my life and my perspective of the world." Another participant commented, “... having an international experience helped me to see the world in a new light with new eyes. I can now think about the world in a global view".

\section{Positive experiences}

There were many comments from alumni about how positive their experiences were. The intensity of positive remarks ranged from "enjoyable" to "life changing" with many identifying their study abroad

Table 2

Qualitative themes listed by ranking.

\begin{tabular}{|c|c|c|c|c|}
\hline Rank & Qualitative theme & Brief description & $\begin{array}{l}\text { Number of } \\
\text { responses }\end{array}$ & $\begin{array}{l}\text { Percentage of } \\
\text { responses }\end{array}$ \\
\hline 1 & Increased understanding & Increased understanding and appreciation for differing cultures and health care systems & 67 & $14.6 \%$ \\
\hline 2 & Expanded awareness & Gained new knowledge, had eyes opened, greater perspective, transformation & 66 & $14.4 \%$ \\
\hline 3 & Positive experience & Experience noted as positive, enjoyable, great opportunity or life changing & 57 & $12.4 \%$ \\
\hline 4 & $\begin{array}{l}\text { Increased appreciation for } \\
\text { individual worth }\end{array}$ & Discovered spiritual connectedness and equality with others & 55 & $12.0 \%$ \\
\hline 5 & Gained critical thinking aptitudes & $\begin{array}{l}\text { Increased critical thinking, creativity and problem solving skills including communication } \\
\text { and resourcefulness }\end{array}$ & 52 & $11.3 \%$ \\
\hline 6 & Increased desire to serve & Greater desire to serve in current volunteer activity and future plans for volunteer service & 52 & $11.3 \%$ \\
\hline 7 & Enhanced personal growth & $\begin{array}{l}\text { Increased personal growth including developing caring attributes of appreciation, empathy, } \\
\text { respect and/or love }\end{array}$ & 50 & $10.9 \%$ \\
\hline 8 & Enhanced gratitude & Grateful for personal circumstances, US healthcare system, or economic opportunities & 18 & $3.9 \%$ \\
\hline
\end{tabular}


experience as the highlight of their undergraduate nursing education, with these feelings summed up in this comment from one alumnus:

"I absolutely loved everything about my experience and feel it has not only enhanced my ability to practice culturally competent care as a nurse, but it also had a deep impact on my other areas of my life."

\section{Individual worth}

This theme became evident through participants' comments regarding their spiritual connectedness with others. Alumni identified the concept that all individuals are worthy of equal access to quality health care. Additionally, alumni described their appreciation for the worth of each individual as they built relationships with the people they were caring for. One alumnus stated "... even though we are all from different places, cultures and circumstances we are still brothers and sisters... we may not even understand each other but we can bond on a spiritual level as we serve each other."

\section{Critical thinking aptitudes}

Another identified theme was developing critical thinking abilities. Skills developed included enhanced problem solving capacity such as overcoming communication barriers, making do with limited resources, and creative thinking. Some alumni mentioned the experience promoted team work, and also provided opportunities to improve teaching skills and best practices for humanitarian aid. One alumni who studied locally said, "I didn't go internationally, I studied holistic nursing, but I loved learning about the different beliefs people have about health care. It was neat to go in and observe different types of healing methods."

Alumni also learned to think critically about use of resources. An alumnus commented "I think when you go places that have limited resources and knowledge you have to be creative. All the things usually readily available to you aren't always around. You have to work with your team and figure out how to solve your problems."

\section{Desire to serve}

Gaining an increased desire to serve was identified as a common alumni experience. Alumni responses included both current volunteer activity and future plans for volunteer service as a result of their global health or local experience. Building relationships with the people they were caring for inspired the desire to serve. A comment that highlighted this concept was:

"From this experience, I've felt an increased desire to find ways to use my skills to benefit disadvantaged people in my community by volunteering in clinics and if possible, taking an opportunity someday to once again give service in an international, struggling country."

\section{Caring attributes}

Alumni described developing the caring attributes of appreciation, empathy, respect and love for others. This theme centered on personal insights and resultant changes such as "I became...", "I found myself..." and "I learned..." A representative comment of this theme from one alumnus described the development of caring attributes. "I learned to put myself into someone else's shoes rather than make hasty judgments about them based on my own values. I learned to listen to others opinions outright before challenging them with my own ideas".

\section{Nursing practice}

Another emerging theme was the effect the experience had on participants' nursing practice. Alumni identified increased self-confidence and intellectual development resulting from program participation. They described how their international experience influenced interactions with patients, guided their career trajectory, and enhanced their resume. One alumnus commented:

"I think that the ... [global health requirement] ...is priceless and for many of your students it will be something that helps them standout in their differing communities/careers as they enter their leadership roles throughout life. I'll never forget my experience and it is something that has been an integral part of my nursing career as I participate in the lives of my patients." A comment from another alumnus:"It subtly solidified the population that I wanted to work with when I graduated. I don't think I realized it until closer to graduation but when I looked back on my course, I remembered how much I loved those experiences and those areas that I applied to for a job were definitely influenced."

\section{Gratitude}

The final theme of "Gratitude" was identified through participants' comments regarding thankfulness for personal circumstances, health care in the United States and economic opportunities. Some comments expressed elements of obligation or indebtedness. For example, one alumni wrote:

"This experience constantly reminds me how blessed I am economically even when struggling with a lower income. Even when others may consider my finances low I have what I need and usually some extra. I have seen people who literally do not have enough to meet their needs; it makes me want to be a good steward of my financial blessings and to be generous with others."

\section{Discussion}

Both quantitative and qualitative data showed the positive impact of the course for alumni; they felt strongly about the importance of this course and reported that it increased their resourcefulness, assisting their critical thinking and problem solving abilities. Alumni comments showed that participation in this course shaped their world views, opened their eyes, and increased their awareness of their place in the world. Results of this study concur with Zorn's (1996) findings that alumni who participated in a global health experience as a part of the nursing curriculum view it as "impactful" on their lives.

When looking at the differences between local and international groups, alumni who studied internationally as compared to those who studied locally scored statistically higher in the professional nurse role (5 items), international perspective (7 items), personal development (13 items), and intellectual development ( 4 items). These results support earlier work about the transformation and lasting impact that participation in a study abroad course provides (Fennell, 2009; Kiely, 2005; Kollar \& Ailinger, 2002).

Personal value systems of alumni were greatly influenced as a result of program participation. Alumni reported an increased desire to serve others as their caring attributes increased. They related the experience as relevant to their careers, as it caused them to reassess their outlook on life. Alumni expressed gratitude for their present circumstances as a result of their global health experiences, and recognized the lifechanging, positive experience the required course provided. This mirrors the impact described by other articles on global health and service learning experiences, providing an "indelible mark" on the hearts of the nursing students who participated in them (Kollar \& Ailinger, 2002), with learning that cannot be duplicated by textbooks and guest lecturers (Maten \& Garcia-Maas, 2009).

Alumni who did not travel internationally for the course also had positive experiences. Many alumni felt their "eyes opened" even without leaving the United States, expressing “...there can be so many cultural experiences anywhere you live..." It also helped them to understand their own culture and identify other opportunities. As one 
alumnus said, "I think that [working with Veterans] really opened my eyes to how much more I need to know about my own culture here in the United States. It also showed to me other career opportunities and other interests I may have in nursing."

Limitations of the study include the fact that it encompassed alumni who had attended a religious, private university. It is possible that respondents have a particular awareness or sensitivity that is distinct from the general population. The survey measured personal perceptions, which can be subjective in nature. In addition, the survey is a one-time broad look at individual scores without a pre-test/post-test significance over time.

\section{Conclusion}

Nurses are influenced long term by a dedicated course related to enhancing cultural competency. Nurses are crucial in providing culturally competent care, and it is imperative there is an emphasis on cultural competency within the nursing curriculum. Future nurses must have the ability to deliver culturally sensitive care (Hagen, Munkhondya, \& Myhre, 2009). The dramatic increase in the multiracial population of the United States only places more importance on educating nurses to provide culturally sensitive care. Our findings demonstrate that a required public and global health nursing course which is an integral part of the nursing curriculum can enhance students' personal and professional growth long past their international experience and into their careers. More research should occur that measures long-term effects of cultural awareness education, as well as how such training can be strengthened. Although alumni viewed both local and international experiences as impactful, alumni participating in international experiences seemed to increase more in professional nurse role, international perspective, personal development, and intellectual development which suggests when possible students should have the opportunity to participate in international experiences.

\section{References}

American Association of Colleges of Nursing (2010). Leading initiatives. Cultural competency in nursing education. Retrieved from http://www.aacn.nche.edu/educationresources/cultural-competency

Betancourt, J. R., Green, A. R., Carrillo, J. E., \& Park, E. R. (2005). Cultural competence and health care disparities: Key perspective and trends. Health Affairs, 24(2), 499-505. http://dx.doi.org/10.1377/hlthaff.24.2.499.
Caldwell, P.. \& Purtzer, M. (2014). Long-term learning in a short-term study abroad program: “Are we really truly helping the community?". Public Health Nursing, 32(5), 577-583. http://dx.doi.org/10.111/phn.12168.

DeDee, S., \& Stewart, S. (2003). The effect of student participation in international study. Journal of Professional Nursing, 19(4), 237-242.

Evanson, T. A., \& Zust, B. L. (2006). "Bittersweet knowledge": The long term-effect of an international experience. Journal of Nursing Education, 45(10), 412-419.

Fennell, R. (2009). The impact of an international health study abroad program on university students from the United States. Global Health Promotion, 16(3), 17-23.

Hagen, L., Munkhondya, B., \& Myhre, K. (2009). Similarities and mutual understanding: Exchange experiences in Malawi for host and guest students. International Council of Nurses, 56(4), 476-483.

Huberman, A., \& Miles, M. (1994). Data management and analysis methods. In N. Denzin, \& Y. Lincoln (Eds.), Handbook of Qualitative Research (pp. 428-444). Thousand Oaks, CA. US: Sage Publications, Inc.

Humes, K. R., Jones, N. A., \& Ramirez, R. R. (2011). Overview of race and Hispanic origin: 2010. United States Census Bureau March, 2011. Retrieved from http://www census.gov/prod/cen2010/briefs/c2010br-02.pdf

Kiely, R. (2005). A transformative learning model for service-learning: A longitudinal case study. Michigan Journal of Community Service Learning, 12(1), 5-22.

Kohlbry, P. W. (2016). The impact of international service-learning on nursing Students cultural competency. Journal of Nursing Scholarship, 48, 303-311. http://dx.doi.org/ 10.1111/jnu.12209.

Kollar, S. J., \& Ailinger, R. L. (2002). International clinical experiences: Long-term impact on students. Nurse Educator, 27(1), 28-31.

Kulbok, P. A., Mitchell, E. M., Glick, D. F., \& Greiner, D. (2012). International experiences in nursing education: A review of the literature. International Journal of Nursing Education Scholarship, 9(1), 1-21.

Maten, A. T., \& Garcia-Maas, L. (2009). Dutch advanced nursing practice students: Role development through international short-term immersion. Journal of Nursing Education, 48(4), 226-231.

National League of Nursing (2009). Diversity Toolkit. Retrieved from http://www.nln org/docs/default-source/professional-development-programs/diversity_toolkit.pdf? sfvrsn $=4$

Peek, E. H., \& Park, C. S. (2013). Effects of a multicultural education program on the cultural competence, empathy and self-efficacy of nursing students. Journal of Korean Academy of Nursing, 43(5).

Riner, M. E. (2011). Globally engaged nursing education: An academic program framework. Nursing Outlook, 59, 308-317.

Smith, K., \& Curry, K. (2011). Is it worth it? Measuring the long-term effects of an international experience for nursing students in Ecuador. Journal of Community Health Nursing, 28, 14-22.

SPSS Inc. (2007). SPSS for windows (version 16.0). Chicago: SPSS Inc.

U.S. Department of Health and Human Services (2011). Agency for Healthcare Research and Quality 2010 national healthcare quality report (AHRQ publication no. 110004). Retrieved from Agency for Healthcare Research and Quality Website: www. ahrq.gov/qual/qrdr10.htm

Zorn, C. (1996). The long-term impact on nursing students of participating in international education. Journal of Professional Nursing, 12(2), 106-110. 